\title{
NOTES
}

\section{Screening and Investigation of Dye Decolorization Activities of Basidiomycetes}

Kouichi Nozaki, ${ }^{1 *}$ Chee Hai Beh, ${ }^{1}$ Masahiro Mizuno, ${ }^{1}$ Tetsuhiro Isobe, ${ }^{2}$ Masahiro Shiroishi, ${ }^{3}$ Takahisa Kanda, ${ }^{1}$ and Yoshihiko Amano ${ }^{1}$

Department of Chemistry and Material Engineering, Faculty of Engineering, Shinshu University, 4-17-1 Wakasato, Nagano 380-8553, Japan, ${ }^{1}$ Technical Development Admin. Tsukuba Research Laboratories, Toyo Ink MFG. Co., Ltd., 27 Wadai, Tsukuba, Ibaraki 300-4247, Japan, ${ }^{2}$ and Agricultural Technology Institute of Nagano Farmers' Federation, 787-1 Ooaza Suzaka, Suzaka 382-0084, Japan ${ }^{3}$

Received 16 August 2007/Accepted 19 October 2007

[Key words: dye decolorization, laccase, bioremediation, basidiomycete]

${ }^{*}$ Corresponding author. e-mail: knoza@shinshu-u.ac.jp phone: +81-(0)26-269-5396 fax: +81-(0)26-269-5394

Abbreviation: ABTS, 2,2'-azino-bis(3-ethylbenzothiazoline-6-sulfonic acid). 
The decolorization of industrial dyes was investigated using extracellular enzymes produced by 21 basidiomycetes, mainly edible mushrooms. Among the 27 dyes used in this study, nine were decolorized by over $\mathbf{4 0 \%}$. Most fungi decolorized Acid Orange 20, but they showed different specificities in the case of the other dyes. Determination of activity staining by native polyacrylamide gel electrophoresis revealed that all the decolorization activities corresponded to ABTS oxidation activities. 
Industrial dyes are released into the environment as wastewater by industries. The colored water evokes an unpleasant feeling even if it is only slightly visible.

Moreover, some of them are stable against light, temperature and biodegradation, and have accumulated in the environment as recalcitrant compounds. Bioremediation may be the most effective method of treating such contaminants. However, dyes within wastewater are poorly decolorized by aerobic biotreatments $(1,2)$, and thus, useful microbes or enzymes that are readily available for conventional processing should be developed.

White-rot fungi are a class of microorganisms that produce efficient enzymes capable of decomposing dyes under aerobic conditions. They produce various oxidoreductases that degrade lignin and related aromatic compounds. They are also expected to be used for the degradation of many pollutants such as dioxins (3), PCB (4), and other recalcitrant or toxic substances $(5,6)$. Particularly, the decolorization of azo dyes has been mainly studied $(7,8)$. In the study of phenol oxidoreductases, industrial dyes are expected to be an available substrate because most of them are aromatic compounds with various substitution groups, and many types with a structural resemblance are available on the market. Moreover, the ability of enzyme to degrade such dyes can be easily determined by measuring the dye decolorization. However, there are few studies on the possibility of dye decomposition except for the monoazo group. In addition, microorganisms involved in degradation have been limited to certain fungi. In this study, the decolorization ability of 27 types of dye was investigated using the extracellular enzymes produced by 21 basidiomycetes. Furthermore, the substrate specificity and the relationship of the enzymes to the ligninolytic enzymes were determined.

Table 1 shows the 27 dyes used in this study and their abbreviations. The basidiomycetes shown in Table 2 were inoculated into $15 \mathrm{~g}$ of wheat bran with $64 \%$ moisture in a $100 \mathrm{ml}$ Erlenmeyer flask. The culture was carried out at $20^{\circ} \mathrm{C}$ for $30 \mathrm{~d}$. Extracellular enzymes were prepared at $4^{\circ} \mathrm{C}$ by stirring the medium at $120 \mathrm{rpm}$ with $50 \mathrm{ml}$ of $20 \mathrm{mM}$ ammonium acetate buffer (pH 5.0) in the flask. After $10 \mathrm{~min}$, the suspension was centrifuged at $15,000 \mathrm{rpm}$ at $4^{\circ} \mathrm{C}$ for $30 \mathrm{~min}$ and the supernatant was used for the experiment.

$\leftarrow$ Table 1 and 2

The decolorization activities of the enzymes produced by the 21 basidiomycetes were investigated using 27 types of dye at pHs 3.0, 5.0 and 7.0. These were determined by measuring the absorbance of the dye at $\lambda_{\max }\left(\lambda_{\max }\right.$ at $\mathrm{pH} 5.0$ is indicated in Table 1). After the incubation of the reaction mixture for $24 \mathrm{~h}$ at $30^{\circ} \mathrm{C}$ in the dark, the percentage decrease in absorbance was determined using a microplate reader (Sunrise Rainbow Thermo; Tecan, Lausanne, Switzerland). Among the 27 dyes, only nine shown in Table 3 were decolorized by more than $40 \%$ by any fungus. The decolorization might have been caused by enzyme action because the decolorization was not shown using a heat-denatured extract. Among all the dyes, AO20 was strongly decolorized by most fungi at approximately $\mathrm{pH} 3.0$ to 5.0. However, various specificities were observed in the case of the other dyes. Lentinus edodes showed high activity against all dyes listed in Table 3. Agaricus bisporus, Armillariella mellea, Lampteromyces japonicus, Panellus serotinus and Pleurotus ostreatus decolorized both phthalocyanine and triphenylmethane dyes by more than $70 \%$. Pleurotus salmoneostramineus was most effective for the two phthalocyanine dyes, and the decolorization reached more than $90 \%$ (DB86 and PB). The optimum 
pHs for the decolorization of these dyes were also around 3.0 to 5.0.

To investigate the relationship between the decolorization and the ligninolytic enzyme activities, the six fungi that had different decolorization activities were used for the following experiment. Lignin peroxidase (LiP) and manganese peroxidase (MnP) activities were assayed according to a previous report (9). The ABTS oxidation activity (10) was assayed as an index of laccase (Lcc) and other oxidoreductases. All fungi showed ABTS oxidation activity but not other ligninolytic enzyme activities. The ABTS activities were 53 (A. bisporus), 5.0 (L. japonicus), 19 (L. edodes), 0.83 (P. serotinus), 6.2 (P. ostreatus) and 1.9 (P. salmoneostramineus) $\mathrm{U} / \mathrm{ml}$. The low $\mathrm{MnP}$ activity $(0.26 \mathrm{U} / \mathrm{ml})$ was found only in the case of $P$. ostreatus. Particularly, A. bisporus and L. edodes showed high activity against ABTS. However, these did not correlate with the dye decolorization activity at all. These facts suggest that the decolorization might be caused by Lcc or other types of oxidoreductase with different substrate specificities. Among these fungi, the characteristics or the gene sequences of some Lcc produced by $A$. bisporus $(11,12)$, L. edodes (13) and $P$. ostreatus (14) have been reported. Particularly, Lcc 1 from $L$. edodes was reported to be effective in some dyes without the need for mediators (15). Some Lcc isozymes also show different specificities against various phenolic compounds (16). $\leftarrow$ Fig. 1

The determination of activity staining by native polyacrylamide gel electrophoresis was performed using the four dyes that decolorized well (Fig.1). These dyes, namely AO20, DB1, DB86 and BG1, are monoazo, diazo, phthalocyanine and triphenylmethane dyes, respectively. After electrophoresis under alkaline native conditions, the gel was incubated for $15 \mathrm{~min}$ in $20 \mathrm{mM}$ sodium acetate buffer ( $\mathrm{pH}$ 5.0) containing $2 \mathrm{mM}$ ABTS, $25 \mathrm{mM}$ AO20, 0.6 mM DB1, $25 \mathrm{mM}$ DB86 or $10 \mathrm{mM}$ BG1. In the case of the dyes, the gel was then transferred to the same buffer lacking the dye and incubated until the band appeared. When ABTS was used as a substrate, one or more activity bands were observed in most fungi. Some of the activity bands showed diffused or heterogeneous bands with different mobilities. These might be some isoforms with different glycosylation or modifications such as by proteolysis. When dye was used as a substrate, decolorized and discolored bands were observed, the latter also being decolorized after further incubation. All activity bands corresponded completely to that of ABTS oxidation. For all the fungi used, the activity bands were divided into two groups according to their specificity. The first included bands B, E, F, G, J, K and L, which showed a wide specificity against most dyes used in Fig. 1. Exceptionally, bands J and L had no ability to decolorize BG1. The second group, including bands A, C, D, H, I and M, was almost specific for some dyes. Among these, all bands except for $\mathrm{C}$ showed the ability to decolorize AO20 alone. A pair of these groups was present in all the fungi except for L. edodes, which abundantly showed a single decolorization activity. It seemed that the $\mathrm{F}$ band showed higher activity against ABTS than the other dyes. In contrast, bands J and L decolorized the dyes well despite the low ABTS activity. In the assay by absorbance measurement, all the fungi decolorized all the dyes (data not shown). The decolorization developed proportionally with incubation time.

The chemical structure of the dyes affected the decolorization. AO7 was negligibly decolorized and the decolorization percentage was less than $20 \%$ for all fungi. Its structure is very similar to that of AO20, but the hydroxyl group in the naphthalene ring binds to a different site (o-position). A similar result was also 
observed in the case of diazo dyes. DB1 and DB15 contain the same methoxyl groups but the positions of the sulfo groups are different. DB6 also has the same structure as DB15 except for the absence of methoxyl groups. Among these dyes, only DB1 was decolorized well. In the case of triphenylmethane dyes, the length of the alkyl side chain might affect the decolorization. BG1, which contains diethylamino groups, showed more decolorization than BB1 and BV3 which contain dimethylamino groups. These structures might be similar to that of phenylpropanoid, a major component of lignin. To investigate the structure essential for decolorization, further studies using more types of dye would be necessary. The information that we obtained might be applicable to the design of various biodegradable compounds.

In this experiment, some effective enzymes for decolorization were selected. These are expected to be used not only for dye decolorization but also for the removal of other contaminants. The addition of a mediator also extends the reactivity widely, and allows for the decomposition of various substances (17).

This work was supported by the Foundation of Kurita Water and Environment.

\section{REFERENCES}

1. Shaul, G. M., Holdsworth, T. J., Dempsey, C. R., and Dostal, K. A.: Fate of water soluble azo dye in the activated sludge process. Chemosphere, 22, 107-119 (1991).

2. Willmott, N., Guthrie, J., and Nelson, G.,: The biotechnology approach to colour removal from textile effluent. J. Soc. Dyers Colour, 114, 38-41 (1998).

3. Bumpus, J. A., Tien, M., Wright, D., and Aust, S. D.: Oxidation of persistent environmental pollutants by a white rot fungus. Science, 228, 1434-1435 (1985).

4. Novotny, C., Vyas, B. R., Erbanova, P., Kubatova, A., and Sasek, V.: Removal of PCBs by various white rot fungi in liquid cultures. Folia Microbiol. (Praha), 42, 136-140 (1997).

5. Cameron, M. D., Timofeevski, S., and Aust, S. D.: Enzymology of Phanerochaete chrysosporium with respect to the degradation of recalcitrant compounds and xenobiotics. Appl. Microbiol. Biotechnol., 54, 751-758 (2000).

6. Bogan, B. W. and Lamar, R. T.: Polycyclic aromatic hydrocarbon-degrading capabilities of Phanerochaete leavis HHB-1625 and its extracellular ligninolytic enzymes. Appl. Environ. Microbiol., 62, 1597-1603 (1996).

7. Knapp, J. S., Newby, P. S., and Reece, L. P.: Decolorization of dyes by wood-rotting basidiomycete fungi. Enzyme Microb. Technol., 17, 664-668 (1995).

8. Swamy, J. and Ramsay, J. A.: Effects of glucose and $\mathrm{NH}_{4}{ }^{+}$concentrations on sequential dye decolorization by Trametes versicolor. Enzyme Microb. Technol., 25, 278-284 (1999).

9. Tien, M. and Kirk, T. K.: Lignin degrading enzyme from Phanerochaete crysosporium: purification, characterization and catalytic properties of unique $\mathrm{H}_{2} \mathrm{O}_{2}$-reqiring oxygenase. Proc. Natl. Acad. Sci. USA, 81, 2280-2284 (1983).

10. Bourbonnais, R. and Paice, M. G..: Oxidation of non-phenolic substrates: an expanded role for laccase in lignin biodegradation. FEBS Lett., 267, 99-102 (1990).

11. Wood, D. A.: Production, purification and properties of extracellular laccase of 
Agaricus bisporus. J. Gen. Microbiol., 117, 327-338 (1980).

12. Perry, C. R., Smith, M., Britnell, C. H., Wood, D. A., and Thurston, C. F.: Identification of two laccase genes in the cultivated mushroom Agaricus bisporus. J. Gen. Microbiol., 139, 1209-1218 (1993).

13. Nagai, M., Sato, T., Watanabe, H., Saito, K., Kawata, M., and Enei, H.: Purification and characterization of an extracellular laccase from the edible mushroom Lentinula edodes, and decolorization of chemically different dyes. Appl. Microbiol. Biotechnol., 60, 327-335 (2002).

14. Giardina, P., Palmieri, G., Scaloni, A., Fontanella, B., Faraco, V., Cennamo, G., and Sannia, G.: Protein and gene structure of a blue laccase from Pleurotus ostreatus. Biochem. J., 341, 655-663 (1999).

15. Nagai, M., Sato, T., Watanabe, H., Saito, K., Kawata, M., and Enei, H.: Purification and characterization of an extracellular laccase from the edible mushroom Lentinula edodes, and decolorization of chemically different dyes. Appl. Microbiol. Biotechnol., 60, 327-335 (2002).

16. Ollikka, P., Leppanen, V. M., Anttila, T., Suominen, I.: Purification of major lignin peroxidase isoenzymes from Phanerochaete chrysosporium by chromatofocusing. Protein Expr. Purif., 6, 337-342 (1995).

17. Soares, G. M., de Amorim, M. T., and Costa-Ferreira, M.: Use of laccase together with redox mediators to decolourize Remazol Brilliant Blue R. J. Biotechnol., 89, 123-129 (2001). 


\section{Figure legend}

FIG. 1. Activity staining against ABTS oxidation and dye decolorization. Native PAGE was performed for $3 \mu \mathrm{g}$ of the protein using $7.5 \%$ polyacrylamide gel. The gels were incubated with ABTS (lane 2), AO20 (lane 3), DB1 (lane 4), DB86 (lane 5) and BG1 (lane 6) at $30^{\circ} \mathrm{C}$. Proteins were stained with CBB RS-250 (lane 1). The decolorized bands are indicated by the bands A-M. 
TABLE 1. List of dyes used in this study

\begin{tabular}{|c|c|c|c|c|c|}
\hline Dye & $\begin{array}{l}\text { Color } \\
\text { Index no. }\end{array}$ & $\begin{array}{r}\lambda_{\max }{ }^{*} \\
(\mathrm{~nm})\end{array}$ & Dye & $\begin{array}{l}\text { Color } \\
\text { Index no. }\end{array}$ & $\begin{array}{r}\lambda_{\max }{ }^{*} \\
(\mathrm{~nm})\end{array}$ \\
\hline Monoazo dyes & & & Phthalocyanine dyes & & \\
\hline Acid Orange $20(\mathrm{AO} 20)$ & 14600 & 476 & Direct Blue 86 (DB86) & 74180 & 623 \\
\hline Acid Orange 7 (AO7) & 15510 & 485 & Phthalocyanine Blue (PB) & 74220 & 624 \\
\hline Pigment Red 57 (PR57) & 15850 & 502 & & & \\
\hline Acid Red 26 (AR26) & 16150 & 502 & Triphenylmethane dye & & \\
\hline Acid Violet 3 (AV3) & 16580 & 552 & Basic Blue 1 (BB1) & 42025 & 630 \\
\hline Mordant Blue 13 (MB13) & 16680 & 525 & Basic Green 1 (BG1) & 42040 & 626 \\
\hline \multirow[t]{2}{*}{ Acid Red 1 (AR1) } & 18050 & 510 & Basic Violet 2 (BV2) & 42520 & 545 \\
\hline & & & Basic Violet 3 (BV3) & 42555 & 587 \\
\hline Diazo dyes & & & Acid Blue 90 (AB90) & 42655 & 583 \\
\hline Direct Blue 2 (DB2) & 22590 & 568 & Mordant Blue 1 (MB1) & 43830 & 438 \\
\hline Direct Blue 6 (DB6) & 22610 & 575 & Mordant Blue 25 (MB25) & 43825 & 434 \\
\hline Direct Blue 3 (DB3) & 23705 & 534 & Acid Blue 9 (AB9) & 42090 & 625 \\
\hline Direct Blue 14 (DB14) & 23850 & 594 & Acid Green 9 (AG9) & 42100 & 633 \\
\hline Direct Blue 15 (DB15) & 24400 & 596 & & & \\
\hline \multirow[t]{2}{*}{ Direct Blue 1 (DB1) } & 24410 & 619 & Triazine dyes & & \\
\hline & & & Basic Dye (BD) & 52010 & 645 \\
\hline Acridine dye & & & Basic Blue 9 (BB9) & 52015 & 663 \\
\hline Basic Orange 14 (BO14) & 46005 & 471 & & & \\
\hline
\end{tabular}

* $\lambda_{\max }$ was determined at $\mathrm{pH}$ 5.0. The abbreviations of the dyes are shown in parentheses. 
TABLE 2. List of basidiomycetes used in this study

\begin{tabular}{llll}
\hline No. & Name & No. & Name \\
\hline 1 & Agaricus bisporus & 12 & Mycoleptodonoides aitchisonii \\
2 & Armillariella mellea & 13 & Naematoloma sublateritium \\
3 & Coriolus versicolor & 14 & Panellus serotinus \\
4 & Flammulina velutipes (cultivation type) & 15 & Pholiota aurivella \\
5 & Flammulina velutipes (wild type) & 16 & Pholiota malicola \\
6 & Grifola frondosa & 17 & Pholiota nameko \\
7 & Ischnoderma resinosum & 18 & Phyllotopsis nidulans \\
8 & Lampteromyces japonicus & 19 & Pleurotus eryngii \\
9 & Lentinus edodes & 20 & Pleurotus ostreatus \\
10 & Lentinus lepideus & 21 & Pleurotus salmoneostramineus \\
11 & Lyophyllum ulmarium & & \\
\hline
\end{tabular}


TABLE 3. Dye decolorization activities of crude extracts from basidiomycetes

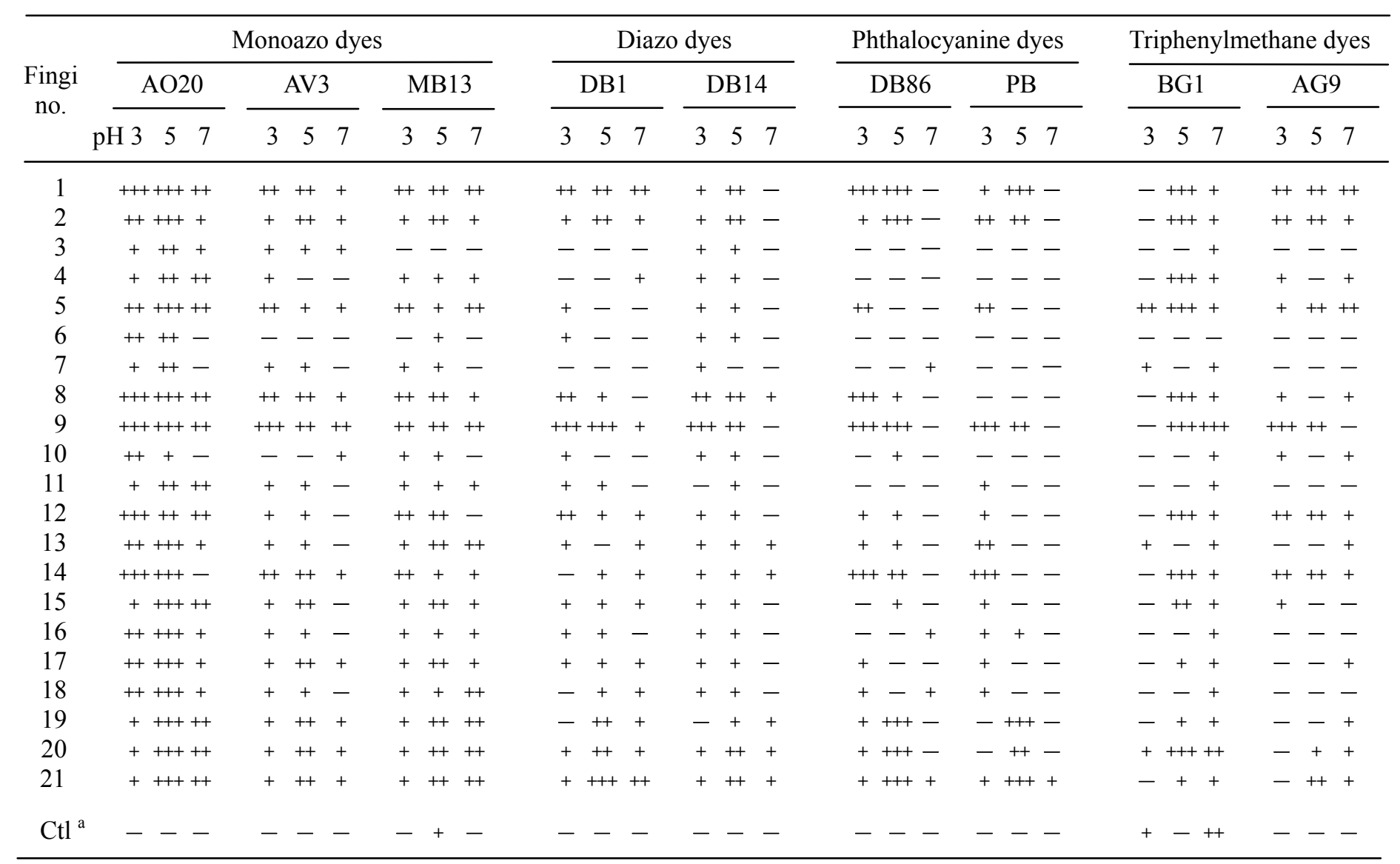

The reaction mixture $(0.1 \mathrm{ml})$ consisted of the crude extract containing $0.6 \mu \mathrm{g}$ of protein and $0.1 \mathrm{mM}$ dye in $10 \mathrm{mM}$

Britton-Robinson's buffer ( $\mathrm{pH} 3,5$ or 7, respectively). The activities are indicated as the decolorization percentage: $0-9 \%$, $-; 10-40 \%,+; 41-70 \%,++; 71-100 \%,+++$. The abbreviations of the dyes follow those shown in Table 1.

${ }^{\mathrm{a}}$ The heat-denatured crude extracts were incubated with the dyes. 

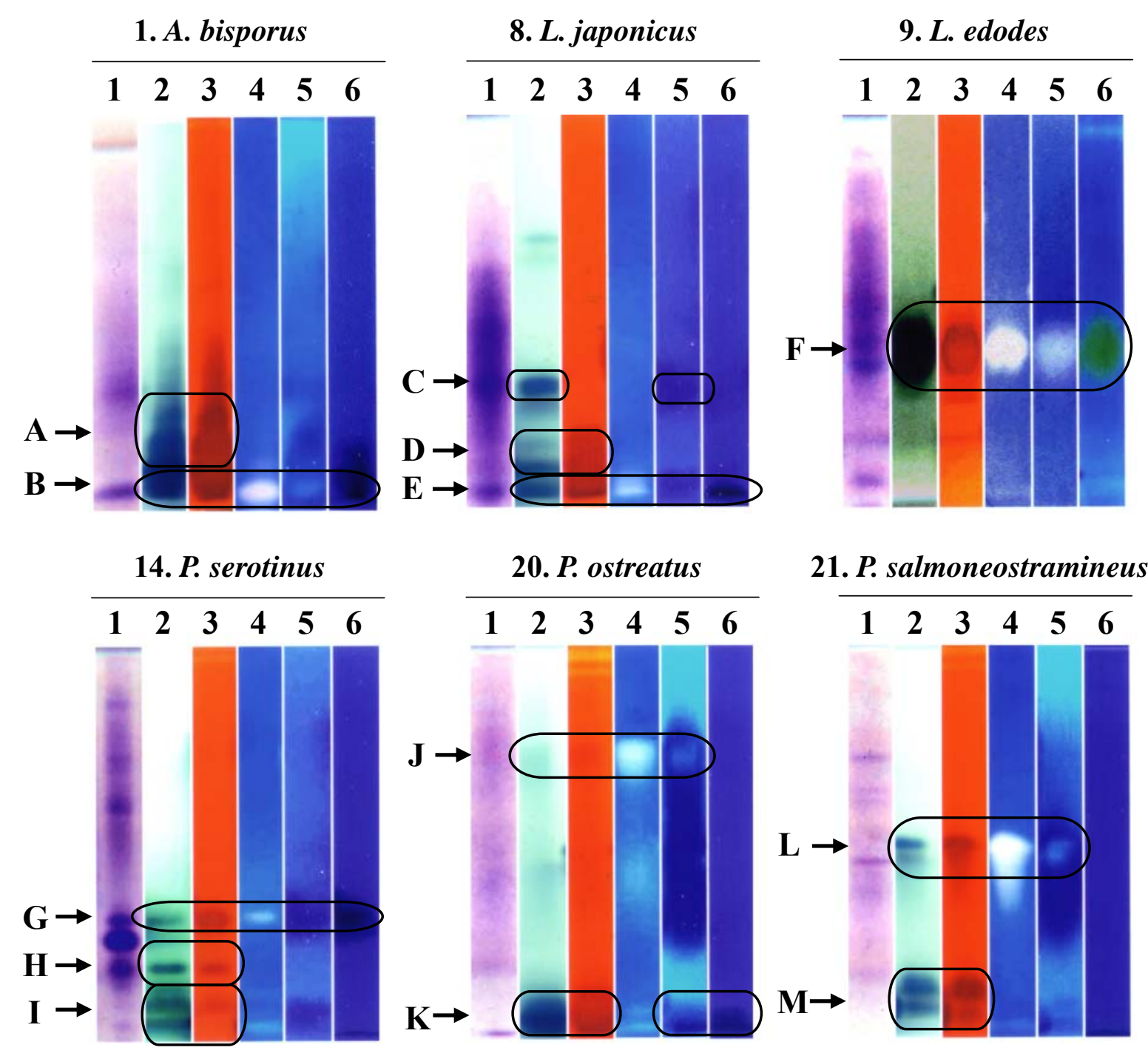

FIG 1 Nozaki et al. 